\title{
Moving toward a predictive and personalized clinical approach in amyotrophic lateral sclerosis: novel developments and future directions in diagnosis, genetics, pathogenesis and therapies
}

\author{
Beatrice Nefussy • Vivian E. Drory \\ Received: 31 March 2010 /Accepted: 19 May 2010/Published online: 9 June 2010 \\ (C) European Association for Predictive, Preventive and Personalised Medicine 2010
}

\begin{abstract}
Amyotrophic lateral sclerosis (ALS) is a rare neurodegenerative disease that affects upper and lower motor neurons in the brain and spinal cord, with progressive weakness and atrophy of most muscles in the body and is almost always fatal within 3-5 years. A small proportion of cases are familial, and remarkable achievements have been made during the last years in understanding the genetics of the disease. In spite of this, the basic pathogenic mechanisms underlying the sporadic disease are still poorly understood. There is urgent need for better understanding of the pathogenic processes in order to be able to develop effective treatments. The present review will focus on recent knowledge gained in diagnosis, genetics, pathogenesis and therapies in ALS. Future development of diagnostic technologies integrating genetic, environmental and individual information will enable us to predict a population at risk for ALS. New treatments actually in development will help improve the medical management of ALS patients, taking into consideration individual traits, as genetic background, and pave a way for a more effective personalized diagnostic and treatment approach.
\end{abstract}

B. Nefussy $(\bowtie) \cdot$ V. E. Drory

Neuromuscular Service, Department of Neurology,

Tel-Aviv Sourasky Medical Center,

6, Weizmann st,

64239 Tel-Aviv, Israel

e-mail: vdrory@post.tau.ac.il

B. Nefussy $\cdot$ V. E. Drory

Sackler Faculty of Medicine, Tel-Aviv University,

Tel-Aviv, Israel
Keywords Amyotrophic lateral sclerosis $\cdot$ Motor neuron disease · Neurodegeneration · Genetics · Epidemiology · Predictive diagnosis $\cdot$ Personalized treatment

\section{Background}

Amyotrophic Lateral Sclerosis (ALS), also known as Lou Gehrig's disease or Maladie de Charcot, is a progressive, fatal neurodegenerative disease, which causes premature selective death of motor neurons in the primary motor cortex, corticospinal tracts, brainstem and spinal cord. It affects lower motor neurons (LMN) that reside in the anterior horns of the spinal cord and in the brain stem; corticospinal upper motor neurons (UMN) that reside in the precentral gyrus of the brain cortex; and, frequently, prefrontal motor neurons that are involved in planning or orchestrating the work of both UMN and LMN [1]. It progresses rapidly to cause denervation and ultimately weakness of most muscles of the body. The disease is almost always fatal and results in death due to paralysis of the respiratory muscles within 3-5 years of onset [2].

\section{Epidemiology}

The incidence of ALS is around 1.8-2.5 per 100,000/year and is evenly distributed across Europe and North America [3]. An unusually high incidence was reported around the Pacific ring, on Guam [4], and the Kii peninsula in Japan [5]. Men are slightly more affected than women, with a male: female ratio about $1.5: 1$, although more recent data suggest that this ratio is smaller, approaching one $[6,7]$. The age of onset of sporadic ALS is very variable, from the third to the ninth decade, with a mean of 63 years [8]. 


\section{Clinical features}

The clinical features of ALS are a direct consequence of the progressive loss of upper and lower motor neurons, with secondary denervation and subsequent reinnervation of muscles. As long as reinnervation can compensate for denervation, clinical weakness may not be detectable. However, as the motor units grow larger and their number begins to decrease, the earliest consequence is that affected muscles may fatigue faster than muscles with normal motor units; consequently, one of the first symptoms of ALS may be increased fatigue. As the number of motor units innervating a muscle decreases further, reinnervation is no longer able to compensate for denervation, permanent weakness develops and progresses and the affected muscles gradually undergo atrophy.

The parts of the body affected by early symptoms in ALS depend on which motor neurons are damaged first. In about $75 \%$ of patients the disease starts with weakness of lower or upper limb muscles, and patients experience tripping or stumbling, difficulty with tasks such as buttoning a shirt or writing. Affected muscles may develop twitching, cramping, or stiffness (limb form). In the other $25 \%$ of cases the site of onset is the motor nuclei in the brainstem and/or their coticobulbar neurons. These patients experience first slurred and nasal speech, followed by difficulty speaking clearly, difficulty swallowing and loss of tongue mobility (bulbar form).

Regardless of the region of the body first affected, muscle weakness and atrophy spread to other regions of the body as the disease progresses. Patients experience increasing difficulty moving, swallowing (dysphagia), and speaking or forming words (dysarthria). The ineffective swallowing of saliva leads to excessive drooling (sialorrhea). Weakness of breathing muscles leads to respiratory insufficiency.

At neurological examination, a combination of UMN and LMN signs can be found: symptoms of UMN involvement include increased muscle tone (spasticity), exaggerated reflexes (hyperreflexia), pathological pyramidal signs such as extensor plantar responses, loss of dexterity in the presence of normal strength. Symptoms of LMN degeneration include muscle atrophy (Fig. 1) and twitching (fasciculations), diminished to absent tendon reflexes. Fasciculations are not specific for ALS, but can be found in other peripheral nervous system diseases and also at times in healthy individuals, although a finding of large and fast-firing fasciculations at many sites is very indicative for the disease.

Around $15-45 \%$ of patients experience uncontrollable emotional symptoms, as inappropriate laughter, crying or smiling, a feature that is associated with speech and swallowing disturbances in the complex of pseudobulbar syndrome, characteristic of bilateral corticobulbar tracts involvement.

Although the sequence of emerging symptoms and the rate of disease progression are variable, most patients will

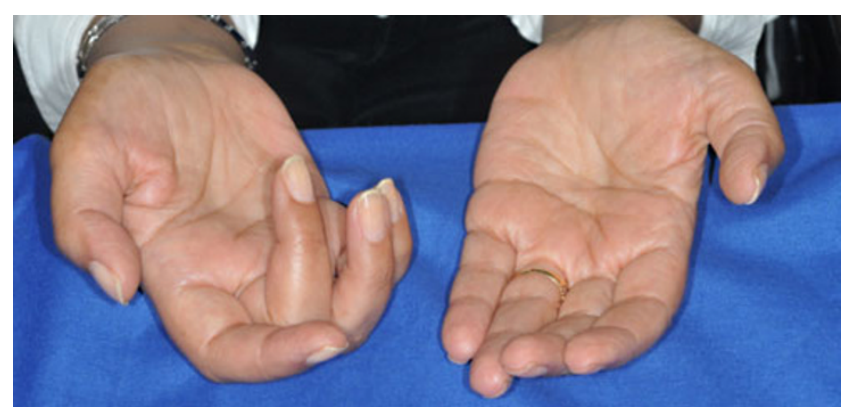

Fig. 1 Atrophy of thenar eminence and weakness of finger extensors, more prominent on the right, in a 70-years-old woman with symptoms of ALS for 6 months

develop with time major disability in all motor tasks, will not be able to stand or walk, or use their hands and arms. Difficulty swallowing and chewing impair the patient's ability to eat and increase the risk of choking and pulmonary infections. Loss of weight is a consequence of impaired nutrition and muscle wasting. Because the disease usually does not affect cognitive abilities, patients are aware of their progressive loss of function and may become anxious and depressed. On the other hand, the preserved cognition enables patients to take decisions, including those related to their own end-of-life, by themselves, even after they reach a totally immobile state (locked-in).

Up to $50 \%$ of patients experience mild difficulties with word generation, attention, or decision making. 5-10\% develop overt frontotemporal dementia, characterized by personality changes and impairment of executive functions and language; this is more common among those with a family history of dementia [9].

As the diaphragm and intercostal muscles weaken, forced vital capacity and inspiratory pressure diminish. Most patients with ALS die of respiratory failure or pneumonia [10]. Death usually occurs within two to five years of diagnosis (median 27 months). Less than $5 \%$ of patients survive more than 10 years. $6 \%$ have an arrested form of disease. In general, survival is better for younger patients and those with limb onset [11].

Interestingly, there are few motor functions that are usually not affected in ALS: control of eye muscles is the most preserved function, although some patients with an extremely long duration of disease (more than 20 years) may lose eye control too. Bladder and bowel control are usually preserved as well, although as a result of immobility and diet changes, intestinal problems such as constipation can require intensive management.

\section{Diagnosis}

Diagnostic criteria for ALS were developed by expert consensus (El Escorial criteria, [12]). By El Escorial criteria 
the diagnosis of ALS requires all of the following: evidence of UMN degeneration by clinical examination, evidence of LMN degeneration by clinical, electrophysiological or neuropathological examination, evidence of progressive spread of symptoms or signs within a region or to other regions, in the absence of electrophysiological, neuroimaging and pathological evidence of other disease processes that might explain the clinical picture.

The El Escorial criteria define categories of clinical diagnostic certainty. For this purpose four body regions were defined: bulbar, including tongue and neck muscles, cervical, thoracic and lumbar. The diagnosis of ALS should be regarded as definite when UMN and LMN signs are found in three body regions. Probable ALS is defined as either UMN and LMN signs in two regions with at least some UMN signs rostral to LMN signs, or UMN signs in one or more regions and LMN signs by electromyography (EMG) in at least two regions. Possible ALS is the least certain degree and is defined as UMN and LMN signs in a single body region, or UMN signs in two body regions, or UMN and LMN signs in two regions with no UMN signs rostral to LMN signs.

It has to be taken into consideration that the El Escorial criteria were developed for research and may be too restrictive for clinical use. In one series, $44 \%$ of patients did not meet criteria for at least probable ALS at diagnosis, and $10 \%$ did not meet criteria even at death [13].

The most important diagnostic tool in the diagnosis of ALS is the EMG examination. EMG is able to detect signs of a LMN lesion in muscles that are apparently unaffected, therefore increases the degree of evidence of the diagnosis, mainly in patients with a predominantly UMN picture or a clinically restricted syndrome. The required EMG findings by the El Escorial criteria cited above are signs of denervation (fibrillations) aside fasciculations and signs of re-innervation. Another set of electrodiagnostic criteria, termed "Awaji criteria", was proposed recently in order to facilitate earlier diagnostic characterization for clinical purposes. This set of criteria broadens the electrophysiologic characterization of ALS to include signs of chronic denervation as equivalent to clinical signs of LMN involvement. In addition, the same criteria propose that in the context of suspected ALS fasciculation potentials should be considered equivalent to signs of active denervation [14].

Neuroimaging studies and other laboratory tests are used to exclude alternative diagnoses. At times, a brain MRI may show bilateral hyperintensities on fluid-attenuated inversion recovery sequence (FLAIR), corresponding to the degeneration of the corticospinal tracts, but the finding is neither specific, nor frequent enough in order to be of use in the diagnostic confirmatory process [15]. Developments of more advanced neuroimaging techniques for confirmation of subclinical UMN involvement are currently underway, as functional MRI (fMRI) [16] and diffusion-tensor imaging (DTI) [17].

The differential diagnosis includes other diseases of the $\mathrm{UMN}$, as multiple sclerosis, primary lateral sclerosis, degenerative processes of the cervical spinal cord, syringomyelia, and other diseases that lead to muscle weakness and wasting, as inclusion body myositis [18], post-polio-syndrome, multifocal motor neuropathy with conduction block, paraneoplastic LMN syndromes [19]. Rare motor neuron diseases, as spinobulbar muscular atrophy (Kennedy disease) [20], adult GM2 gangliosidosis (hexosaminidase A deficiency) [21], juvenile muscular atrophy of distal upper extremity (Hirayama disease) [22] have to be ruled out in specific patients.

An incorrect diagnosis of ALS can have devastating emotional and social consequences for patients and their families, and it can delay appropriate treatment of an alternative disease process; therefore, it is important to consider diseases that can mimic ALS or that can contribute to the patient's symptoms.

\section{Genetics}

\section{Familial ALS}

Approximately $5-10 \%$ of ALS cases are familial (FALS) with a Mendelian pattern of inheritance. The disease is transmitted in an autosomal dominant fashion in most cases. Mean age at onset is 10-20 years younger in patients with FALS than in patients with sporadic disease, and variability between families is greater than variability within families. Most cases of FALS are indistinguishable from sporadic disease; others have unique phenotypes [23, 24].

The first described and most frequent genetic abnormality is a mutation in the copper/zinc superoxide dismutase (SOD1) gene, on chromosome 21q, found in $10-20 \%$ of familial cases and $2 \%$ of patients with sporadic ALS (SALS) [25]. More than 140 allelic variations have been described in the SOD1 mutants, most of them are single base substitutions leading to an amino acid exchange. It is not yet known how mutant SOD1 causes ALS, but mutations in the gene are thought to cause disease through a toxic gain-of-function rather than causing impairment of the antioxidant function of the SOD1 enzyme [26]. The disease onset and duration are reported to be closely linked to the type of SOD1 mutation. Certain SOD1 mutations are associated with rapidly progressive disease and short survival, like A4V, while others present with a relatively benign course [27].

The discovery that TDP-43 protein, encoded by TARDBP gene on chromosome $1 \mathrm{p}$ (encoding the TAR-DNA binding protein TDP-43), is a constituent of ubiquitinated inclusions 
in the cytoplasm of motor neurons of patients with SALS, as well as in patients with non- SOD1 FALS and patients with frontotemporal lobe dementia (FTLD) $[28,29]$ constituted an important development in ALS research. TDP-43 is an RNA processing protein that is normally found mainly in the cell nucleus. Over 30 dominant mutations of the TARDBP gene have been reported to date, accounting for $3 \%$ of patients with both FALS and SALS [30-32]. A mutant mouse model was recently described that develops a progressive and fatal neurodegenerative disease with both ALS and FTLD features [33].

Mutations in the fused in sarcoma/translated in liposarcoma (FUS/TLS) gene were identified in $4 \%$ of FALS $[34,35]$ and in very few SALS cases [36]. Interestingly, like $T D P-43$, this gene has a putative role in RNA regulation and is similarly translocated from the nucleus to the cytoplasm in spinal cord motor neurons.

Mutations in alsin, vesicle associated membrane protein, angiogenin, senataxin and a mutation in the p150 subunit of dynactin have also been reported in rare cases, and linkages to more loci without identification of a gene have been described (reviewed in 24), but still a majority of patients with FALS harbor a not yet detected genetic defect.

Known genes and linkages associated with familial ALS are summarized in Table 1.

\section{Sporadic ALS}

The causes of SALS are still unknown. It is considered to be a multifactorial disease, in which both environmental and genetic factors interplay to trigger disease onset and progression. The completion of a haplotype map of the human genome [37] and development of advanced genotyping technology have enabled the performance of genotype-wide association studies (GWAS). The genomewide SNP association analysis is a powerful, relatively new method to identify, in an unbiased manner, genetic loci and genes underlying complex diseases. SNP arrays allow large-scale linkage analysis, association, and copy number studies. A number of GWAS have been performed in SALS, however to date these methods have not revealed reproducible potential links to ALS [38-41]. This is due probably to a large degree of genetic heterogeneity as well as to the possibility that disease susceptibility is influenced by additional environmental factors.

An exciting finding was reported by one of the most recent and largest GWAS analyses of SALS to date: although the analysis did not reveal any correlation with risk of disease, it demonstrated for the first time an association between a gene (kinesin-associated protein 3-KIFAP3) and survival. Patients who were homozygotes for the favorable allele of the gene survived on average 14 months longer than heterozygotes and homozygotes for the unfavorable allele. This is the first evidence that genetic factors can modify disease phenotype [42].

A further remarkable finding, with still unclear significance, is that of a specific variant in the chromogranin $B$ (CHGB) gene that is present in $10 \%$ of ALS patients, both sporadic and familial, and in only $4.5 \%$ of controls, conferring a 2.2-fold greater relative risk to develop ALS.

Table 1 Genes and linkages involved in familial ALS

\begin{tabular}{|c|c|c|c|c|c|}
\hline Disease name & Genetic locus & Protein name & Gene symbol & Inheritance & Incidence in familial ALS \\
\hline ALS1 & $21 \mathrm{q} 22.1$ & $\mathrm{Cu}-\mathrm{Zn}$ superoxide dismutase 1 & SOD1 & Dominant & $10-20 \%$ \\
\hline ALS2 & $2 q 33$ & Alsin & $A L S 2$ & Recessive & Rare \\
\hline ALS3 & $18 \mathrm{q} 21$ & unknown & unknown & Dominant & Rare \\
\hline ALS4 & $9 q 34$ & Senataxin & SETX & Dominant & Rare \\
\hline ALS5 & $15 q 15.1-21.1$ & unknown & unknown & Recessive & Rare \\
\hline ALS6 & $16 \mathrm{q} 12$ & Fused in sarcoma & FUS & $\begin{array}{l}\text { Dominant } \\
\text { Recessive }\end{array}$ & $4 \%-5 \%$ \\
\hline ALS7 & $20 \mathrm{p} 13$ & unknown & unknown & Dominant & Rare \\
\hline ALS8 & $20 \mathrm{q} 13.3$ & $\begin{array}{l}\text { Vesicle-associated membrane } \\
\text { protein-associated protein B }\end{array}$ & $V A P B$ & Dominant & Rare \\
\hline ALS9 & $14 \mathrm{q} 11.2$ & Angiogenin & $A N G$ & Dominant & Rare \\
\hline ALS10 & $1 \mathrm{p} 36.2$ & TAR-DNA binding protein 43 (TDP-43) & TARDBP & Dominant & $1-4 \%$ \\
\hline ALS? & $2 \mathrm{p} 13$ & Dynactin 1 & DCTN1 & Dominant & Rare \\
\hline ALS-FTD1 & $9 q 21-22$ & unknown & unknown & Dominant & unknown \\
\hline ALS-FTD2 & $9 p 13.2-21.3$ & unknown & unknown & Dominant & unknown \\
\hline $\begin{array}{l}\text { ALS-FTD with } \\
\text { Parkisonism }\end{array}$ & $17 \mathrm{q} 21.1$ & Microtubule-associated protein tau & $M A P T$ & Dominant & Rare \\
\hline ALS-X & Xcen & unknown & unknown & Dominant & Rare \\
\hline
\end{tabular}

$A L S$ amyotrophic lateral sclerosis; FTD Frontotemporal dementia 
The same variant was associated with an earlier age at onset by almost ten years in both SALS and FALS patients, therefore the CHGB gene is apparently both a susceptibility and a phenotype modifier gene [43]. The results of both last studies await further confirmation from other populations.

\section{Individual risk factors}

It should be remembered that association is not cause, but rather the first step in identifying a possible risk factor. When applying an evidence-based approach to the analysis of the epidemiological data, smoking exposure, including patients who stopped smoking, was the only established exogenous risk factor for occurrence of ALS [44, 45].

No other risk factor has attained this level of certainty regarding its association with ALS. Head trauma, physical activity, residence in rural areas, and alcohol consumption were not proven as risk factors for ALS, although implicated in certain studies [46]. Specific occupational exposures are also mentioned as a risk factor for ALS, although analyses of occupation as potential determinants of ALS did not reach a definitive conclusion [47].

Two putative risk factors that have gained recent attention include military service during the Gulf War $[48,49]$, and being a soccer player $[50,51]$. However, the level of evidence supporting their role in triggering ALS is low $[52,53]$.

The use of statins has been mentioned as possibly associated with an increased incidence of ALS [54], but an analysis by the US Food and Drug Administration (FDA), undertaken after the agency received a higher than expected number of reports of the occurrence of ALS among individuals on statins, failed to reveal an increased incidence of ALS in subjects treated with statins compared with placebo [55].

Individual metabolic traits encountered frequently in the general population were implicated recently as possible modulatory factors, able to influence prognosis in affected individuals. It was shown that an abnormally elevated low-density lipoprotein (LDL) / high-density lipoprotein (HDL) ratio increased mean patient survival by more than 12 months [56]. Another study demonstrated that ALS patients had lower mean serum uric acid levels than healthy individuals. The decreased uric acid levels were correlated to the rate of disease progression [57]. Pre-existent diabetes mellitus was shown to delay the onset of ALS-related symptoms by 4 years in another study [58]. Interestingly, all these metabolic factors are considered detrimental in the daily clinical practice, but for ALS patients they carried a favorable prognosis. Probably they are also interrelated, but were not analyzed as a group yet.

\section{Pathophysiology and pathogenesis}

Involvement of non-neuronal cells

Most insights into the pathogenic mechanisms of ALS in the past decade came from studies in transgenic mice carrying the human SOD1 mutation. SOD1 is a ubiquitously expressed cytoplasmic enzyme that converts superoxide anions to hydrogen peroxide. However, mutant SOD1 confers its toxic properties without altering enzymatic activity [59-62].

A major contribution to understanding disease mechanisms was the discovery that ALS is not just cell-autonomous, but is influenced by the surrounding environment, namely by the interaction between motor neurons and non-neuronal cells, mainly glial cells. Initial experiments that selectively expressed mutant SOD1 in motor neurons or glial cells did not induce motor neuron degeneration or disease [63-65]. An elegant experiment in chimeric ALS mice demonstrated that wild-type non-neuronal cells extended survival of SOD1 mutant motor neurons in ALS mice, implicating that neighboring non-neuronal cells are important in determining survival [66]. The same study reported pathological abnormalities and cell death in wild-type motor neurons adjacent to mutant SOD1-expressing non-neuronal cells. Thus, the vulnerability of motor neurons to SOD1-mediated toxicity appears to be influenced by their cellular environment, created by their adjacent non-neuronal cells. Astrocytes that express mutant SOD1 secrete probably factors that are toxic to motor neurons, although such factors have not yet been identified [67].

It has also been demonstrated that selective reduction in mutant SOD1 expression within microglia [68, 69] and astrocytes [70] significantly slows disease progression, but does not affect the timing of disease onset. Evidence that disease onset might have different genetic and cellular mechanisms than disease progression comes from the recent finding that selective down-regulation of mutant SOD1 solely within the postnatal motor neurons significantly slowed disease onset without affecting disease progression [71].

\section{Glutamate excitotoxicity}

Glutamate-mediated excitotoxicity was the first proposed mechanism of motor neuron degeneration in ALS, following the finding of increased levels of glutamate in the cerebrospinal fluid of ALS patients [72]. ALS has been associated with reductions in the level of the glial cell excitatory amino acid transporter EAAT2 [73]. This defect might lead to an abnormal accumulation of extracellular glutamate and subsequently repetitive firing of motor neurons. 
Free radical damage

The concept that oxidative damage is involved in ALS was based on the discovery that mutations in the SOD1 gene cause FALS. Increased levels of 3-nitrotyrosine, a marker for peroxynitrite-mediated oxidative damage, have been reported in ALS patients [74]. Peroxynitrite causes cell damage by nitration of tyrosine residues in target proteins. We have just recently reported that ALS patients have a significantly lower level of uric acid, a peroxynitrite specific antioxidant, compared to control subjects and that the concentration of uric acid was reversely correlated with the rate of disease progression [57]. Nevertheless, although oxidative damage has been linked to neurodegeneration, many antioxidants tested in clinical trials have failed to show benefit.

\section{Intracellular aggregates}

Ubiquinated inclusions containing pathologic forms of TAR DNA-binding protein-43 (TDP-43) were identified in the cytoplasm of motor neurons of patients with SALS, non-SOD1 FALS and patients with frontotemporal dementia [28, 29, 75, 76]. Cases with SOD1 mutations had ubiquitin-positive neuronal inclusions; however, they were not immunoreactive for TDP-43. These findings implicate a common pathogenesis in SALS and non-SOD1 FALS. In contrast, the absence of pathological TDP-43 in cases with SOD1 mutations implies that motor neuron degeneration in these cases may result from a different mechanism.

\section{Alteration in RNA processing}

Both TDP-43 and FUS/TLS are genes that encode RNA processing proteins [35]. Patients with the FUS/TLS mutations have cytoplasmic inclusions containing FUS/ TLS but not TDP-43. TDP-43 and FUS/TLS have striking structural and functional similarities, implicating alterations in RNA processing as a key event in ALS pathogenesis and as a main target for future therapeutic agents.

\section{Mitochondrial dysfunction}

Morphological and functional defects in mitochondria were found in both human patients and ALS mice. Mutant SOD1 was found to be associated with mitochondria and subsequently impairs mitochondrial function. Recent studies suggest that axonal transport of mitochondria along microtubules and mitochondrial dynamics may be disrupted in ALS (reviewed in [77]). Creatine, an agent that improves mitochondrial function, has been shown to be neuroprotective in animal models of ALS [78]; however, in humans creatine showed only a trend toward beneficial effect in survival and did not influence motor, respiratory or functional measures in ALS patients [79].

Lack of neurotrophic factors, caspase-mediated cell death (apoptosis) and inflammation are also possible mechanisms involved in ALS (reviewed in [80, 81]).

In spite of major scientific achievements in the field during the last years, the exact mechanisms responsible for the onset and progression of motor neuron degeneration remain largely unknown.

\section{Treatment}

The management of ALS nowadays is based on the recognition of the importance of multidisciplinary care. Although there is no cure for the disease, many of the symptoms that develop during the course of the disease are treatable and it is crucial to consider adjunctive measures to maintain function and independence and improve quality of life in patients with ALS. The improvement in symptomatic care of the patients during the last decade led to an improved rate of survival [82].

Non-drug therapy

\section{Ventilatory management}

Respiratory insufficiency is a common feature in patients with ALS, usually in advanced stages, although it may be the presenting clinical symptom in certain cases, and is the most frequent cause of death.

The respiratory status in ALS patients should be monitored serially by measurement of forced vital capacity (FVC) or sniff nasal pressure and questioning the patient about symptoms of respiratory insufficiency such as insomnia, daytime fatigue, morning headaches. Overnight pulse oximetry or polysomnography should be obtained as clinically indicated.

Respiratory rehabilitation therapy such as insufflationexsufflation and chest physiotherapy can help maintain lung function and avoid secondary atelectasis and infections [83].

Non-invasive ventilatory support (NIV) should be considered in patients with symptoms of respiratory insufficiency when FVC (sitting or supine) is at or below $50 \%$ of predicted normal; or if there is evidence of nocturnal hypoventilation $\left(\mathrm{O}_{2}\right.$ saturation $\left.<90 \%\right)$, even if sitting and supine FVC are not significantly reduced.

NIV is usually provided by bi-level positive pressure devices (BiPAP). The rationale of using NIV is that 
non-invasive ventilation can improve survival and quality of life, and postpone the need for tracheostomy [84, 85]. In patients with severe bulbar impairment, NIV improves sleep-related symptoms, but it does not confer a large survival advantage [84].

During the last years it has been recognized that initiation of NIV might be indicated earlier than when FVC drops below 50\% predicted. Patients treated early with NIV had an increased survival at one year and their median decline in FVC was slower than in patients who did not use NIV [86]. A Cochrane review analyzed recently the efficacy of NIV for ALS and concluded that NIV is able to prolong survival and to improve and maintain quality of life [87]. Similarly, a revision of the Practice Parameters of the American Academy of Neurology published in 2009 concluded that NIV is probably effective in prolonging survival and in slowing the rate of FVC decline, and possibly effective in improving quality of life. Therefore NIV should be considered to treat respiratory insufficiency in ALS [88].

A new and different approach that is currently under evaluation is the early (before significant diaphragmatic muscle weakness and atrophy occurred) implantation of electrodes into the diaphragm with subsequent electrical pacing. The consequence of this technique is both an immediate improvement of the diaphragm contraction and inspiratory volume, and a long-term delay in the development of muscle atrophy of the diaphragm with slowing of respiratory deterioration. The technique is apparently safe and reportedly able to postpone invasive mechanical ventilation for up to two years [89].

\section{Nutritional management}

In spite of decreasing movement abilities, patients with ALS have increased needs for energy in form of caloric intake $[90,91]$. On the other hand the caloric intake is frequently low as a consequence of impaired swallowing. Dysphagia is common in ALS and leads to increased risk of aspiration, malnutrition, weight loss and dehydration. Enteral tube feeding is commonly used in ALS to maintain adequate nutrition and hydration. This is most commonly performed by percutaneous endoscopic gastrostomy (PEG) and in fewer cases by radiologically inserted gastrostomy (RIG). Enteral nutrition should be initiated early after symptom onset in order to minimize complications and weight loss. Enteral nutrition via PEG is recommended by the revised Practice Parameters of the American Academy of Neurology, as it stabilizes body weight and improves survival in both bulbar and limb onset patients [88].

\section{Communication}

Verbal communication is for most humans one of the most important functions, as it determines the ability to initiate and maintain social interactions, and dominates the evaluation of percepted quality of life. Patients with bulbar ALS lose their ability to speak relatively early in the course of the disease. If the ability to write or use a keyboard is preserved, patients switch to written communication. But with progressing disease the hands become weak too, and more sophisticated communication aids are needed. Computer interfaces are being developed that can be activated by the patient through fixation with his eyes at a keyboard on a screen (Fig. 2), or even by patient's thought and registration of the pattern of his brain EEG activity [92].

\section{Exercise and physical therapy}

Performance of physical activity was considered in the past as possibly harmful for patients with ALS, but during the last decade there is rather robust evidence that regular moderate exercise is able to decrease the rate of deterioration in disability in ALS patients [93, 94].

Physical therapy is indicated to preserve range of motion of joints and avoid secondary pain, contracture, muscle spasms.

\section{Multidisciplinary care}

Specialized ALS centers were established at many sites throughout US and Europe; they have the experience and resources to manage ALS patients and offer high level standard of care. Multidisciplinary care may have a survival benefit in ALS [95].

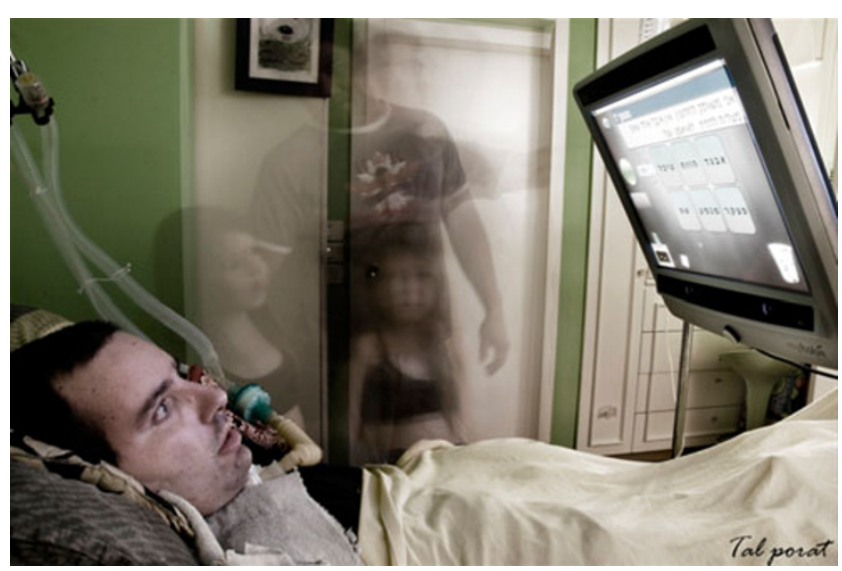

Fig. 2 This 40-years-old patient is completely paralyzed and mechanically ventilated. He chooses letters on a computer screen with light beams refracted by his eye balls. He wrote in this way (in hebrew on the top of the screen): "I am completely paralyzed, there is no single part of my body that I can move" 


\section{Drug therapy}

\section{Contemporary therapies}

Inferences from animal models, including transgenic models of familial disease, to sporadic human disease are not straightforward. However, recognition of the role of glutamate excitotoxicity in sporadic disease and in animal models led to the development of riluzole, the only treatment that has been shown to ameliorate the course of sporadic ALS [96, 97]. The mechanism of action of riluzole includes interference with N-methyl-D-aspartate (NMDA) receptor mediated responses, stabilization of voltage-gated sodium channels, inhibition of glutamate release from pre-synaptic terminals, and increasing extracellular glutamate uptake [98].

Two randomized, controlled clinical trials have shown that riluzole prolongs survival in patients with ALS $[96,97]$. The results of a recent meta-analysis indicate that riluzole at a dose of $100 \mathrm{mg}$ daily is safe and probably prolongs survival by approximately $2-3$ months in patients with ALS [99].

Additional drug therapy exists to manage symptoms of ALS. Adequate symptomatic treatment of ALS can alleviate patient discomfort. Sialorrhea and emotional lability are bothersome and often socially embarrassing to ALS patients. Sialorrhea can be treated with amitriptyline, glycopyrrolate, or transdermal scopolamine patches; if sialorrhea is refractory, radiation therapy of the salivary glands or botulinum toxin injections of the salivary glands can be offered [100]. Thick mucus is amenable with propranolol or metoprolol. Pseudobulbar affect or emotional lability is treated with dextromethorphan/ quinidine, amitriptyline or fluvoxamine.

Anxiety, depression, pain, and muscle discomfort impair quality of life of patients and often of their caregivers. Depression can be treated with tricyclic antidepressants such as amitriptyline or newer agents such as sertraline. Anxiety can be treated with anxiolytics such as benzodiazepines. Pain should be treated with anti-inflammatory and non-narcotic analgesic drugs or combinations; opioid analgesics should be considered if pain is refractory or in later disease stages. Muscle stiffness and spasticity can be treated with muscle relaxants such as baclofen or tizanidine. A recent study showed a positive effect of the anticonvulsant drug levetiracetam on muscle cramps and spasticity [101].

Fatigue may be a disabling symptom unrelated to muscle weakness or quality of sleep; in these patients modafinil may be indicated [102]. Insomnia causes nighttime distress and interferes with daytime functioning and well-being. Insomnia should be treated with non-invasive ventilation, pain management, antidepressants, or hypnotics, depending on the suspected cause.
Future therapies and directions

Despite the advances in understanding disease mechanisms and the performance of many clinical trials, no new therapy for ALS has been discovered during the last 15 years, although few clinical trials gave a slight cause for cautious optimism. Here are some of the more promising novel treatment approaches for ALS:

\section{Drugs intended to lower glutamate exitotoxicity}

Talampanel (Teva) - it is a non-competitive antagonist of $\alpha$-amino-3-hydroxy-5-methyl-4-isoxazolepropionic acid (AMPA). A double-blind, placebo-controlled, randomized clinical trial of nine months duration was conducted in 59 patients with ALS, with 40 subjects receiving talampanel and 19 subjects receiving placebo. Talampanel was well tolerated and although no efficacy measure reached statistical significance, there was a trend towards slower decline of functional measurements and muscle strength [103]. A large phase II trial with more than 500 participants is ongoing. Results are expected mid-2010.

Ceftriaxone (Hoffman LaRoche) - a further drug aimed at glutamate toxicity, used clinically as a wide spectrum antibiotic. In a novel attempt to widen the search for potential therapeutic agents, an in vitro screening of 1040 FDA approved drugs in over 28 assays relevant to various neurodegenerative disorders was performed. Several cephalosporins showed hits in ALS relevant assays. Ceftriaxone is a third generation cephalosporin with good penetration into the central nervous system and a long half-life. It increases expression of the glutamate transporter excitatory amino acid transporter 2 (EAAT2) and glutamate uptake in cultured astrocytes [104]. Ceftriaxone has been shown to triple EAAT2 activity in mouse brains and increased lifespan, strength, and neuron survival in ALS transgenic mice [105]. A Phase I trial and compassionate use study have been completed; a multicenter phase III study, aiming for 600 subjects, started enrolling in May 2009 in order to determine safety and effectiveness of long-term use of the drug in patients with ALS.

The pharamaceutical company Avanir has announced positive results for its phase 3 trial to treat emotional outbursts, with uncontrollable episodes of laughing and crying in patients with ALS and multiple sclerosis using its experimental drug Zenvia. Zenvia is a combination of two drugs, dextromethorphan, which supresses glutamate release, and quinidine, which inhibits the breaking down of dextromethorphan [106]. The drug significantly reduced the number of pseudobulbar episodes compared to placebo. The drug was generally safe and well tolerated. 


\section{Protection of motor neurons}

The experimental compound SB509 (Sangamo BioSciences) appears safe and well-tolerated and may have a positive effect on function in patients with ALS. The compound contains a gene for an activator of vascular endothelial growth factor A (VEGF-A). VEGF-A increases production of blood vessels and may protect or nourish nerve cells. Reduced VEGF-A expression in the spinal cord leads to ALS-like symptoms [107], excess VEGF-A delays neurodegeneration and extends survival in a transgenic mouse model of ALS [108, 109]. In addition, a mutation in the VEGF-A promoter is associated with risk for ALS in males [110]. An open-label Phase II trial with intramuscular injections in the neck, arms and legs or only in the legs in 45 ALS patients is ongoing. Estimated completion date is June 2010.

Arimoclomol activates chaperones - misfolded proteins (reviewed in [111]). According to CytRx, the developing company, arimoclomol can detect proteins that are misfolded and potentially toxic and refold them into their correct, nontoxic shapes. A 3-months phase IIa trial in patients with ALS demonstrated safety of the drug [112] and another study, with participants with FALS caused by mutations in the SOD1 gene, is currently being conducted. A multicenter dose-ranging clinical trial of arimoclomol is planned.

\section{Modulate the mitochondria}

The experimental drug KNS760704 (Knopp Neurosciences) was reported to be safe and well tolerated, and there were indications of possible benefit, in 92 patients with ALS within a nine months trial. KNS760704 is a synthetic aminobenzothiazole with demonstrated activity in maintaining mitochondrial function. It may protect nerve cells under stress. The drug is a molecular mirror image of pramipexole, a prescription medication approved for the treatment of Parkinson's disease and restless legs syndrome [113]. There was a dose-related trend toward a slowed rate of disease progression, and toward a survival benefit in the large dose group compared to the low dose group [114]. The safety results and the trends toward improved functional outcomes and survival provide preliminary evidence supporting the ongoing evaluation of KNS760704 in phase 3 clinical trials.

Olexosime (Trophos) is a small cholesterol-like molecule that was discovered in a screening program aimed at finding small molecules that promote motor neuron survival in culture [115]. Olexosime interacts with the mitochondrial permeability transition pore, possibly preventing it from opening; this might help prevent apoptosis. In SOD1 transgenic mice the compound delayed disease onset and extended survival. Olexosime has completed Phase $\mathrm{Ib}$ studies in ALS patients. These clinical trials demonstrated that the drug is well tolerated and has a good safety profile. Olexosime is currently tested in an ongoing pivotal efficacy study in ALS. Results of this study are expected in mid-2011.

\section{Silence SOD1 gene}

ISIS 333611 from Isis Pharmaceuticals is an antisense oligomer directed at SOD1, aimed to down regulate the gene's expression, as it does in a rat disease model, and slow disease in patients with SOD1 mutations. It is the first approach that is really directed toward a known target for the disease. A multicenter Phase 1 safety trial is enrolling patients with SOD1-related FALS. Estimated completion date is December 2011.

\section{Stem cells}

Stem cell transplantation represents a new therapeutic approach with the opportunity of either cellular replacement, or trophic support for the existing cell population, or both. Potentially pluripotent and multipotent stem cells could be stimulated to develop into specialized cells that represent a renewable reservoir of cells for transplantation. A different approach is trophic and growth factor support, such as delivering brain-derived neurotrophic factor or glial-derived neurotrophic factor.

There are a number of different sources for stem cells, ranging from embryonic, fetal, placental and cord blood to adult tissues. The adult tissue stem cells include bone marrow-derived cell populations such as the marrow mesenchymal stem cells and hematopoietic stem cells, blood hematopoietic stem cells and neuronal stem cells. Adult mesenchymal stem cells may be the best choice for cell therapy assuming that they can be harvested from the patient and grown in sufficient amounts. They offer the advantages of not raising any ethical problems, not inducing immune rejection, are less prone to promote tumors and are easily available.

All cell types can be administered by allogeneic or autologous delivery. Cells can be transplanted intracerebrally or directly into the spinal cord, or infused by an intravenous, intrathecal or intramuscular route. A further approach is mobilization of endogenous progenitor stem cells from the bone marrow into the peripheral blood by cytokines such as granulocyte colony-stimulating factor.

The first FDA approved clinical trial to test stem cell treatment for ALS is ongoing. This phase I trial intends to study the effects of injecting human neural stem cells (Neuralstem) into the spinal cords of patients with ALS. These cells have already shown promise in transgenic SOD1 rats, in which they differentiated into neurons that 
formed synapses with host nerve cells, expressed and released neurotrophic factors and delayed disease onset and progression [116]. The study focuses on the safety of the transplantation procedure.

Stem cells collected from blood [117] and bone marrow [118] have also been tested in ALS. The autologous transplantation of hematopoietic CD133(+) stem cells into the frontal motor cortex was safe and well-tolerated in ALS patients and delayed disease progression [117]. The autologous transplantation of mesenchymal stem cells into the spinal cord of ALS patients seems safe and might be useful for future ALS clinical trials [118].

A different approach is being used by Brainstorm, an Israel-based company that develops mesenchymal stem cell lines that are able to secrete neurotrophic factors. A small clinical trial in ALS patients is planned, with injection of those cells into muscles in an attempt to deliver neurotrophic factors to the anterior horn cells by their uptake into nerve terminals and retrograde axonal transport.

The recent development of induced pluripotent stem cells (iPSC) by re-programming human skin fibroblasts is promising. Dimos et al. [119] demonstrated the feasibility of re-programming adult skin fibroblasts into embryonic stem cells that can subsequently yield patient-specific neural cells (neurons and astroglial cells). They not only demonstrated that human disease-related neural cells can be generated from adult fibroblasts via the generation of iPSC, but also that the method can be successfully applied to fibroblasts derived from elderly patients, a crucial issue for age-dependent diseases. The generation of pluripotent stem cells from an individual patient's somatic tissues would enable large scale production of the cell types affected by the patient's disease. These cells could in turn be used for better understanding of disease mechanisms, drug development and autologous cell replacement therapies.

\section{Conclusions and prospects for the future}

The last decade of basic and clinical research was very fruitful for the ALS community, with plenty of exciting news that improve our understanding on the different aspects of this dreadful disease. We are at the edge of a new era, as we just begin to understand the basic processes that lead to individual differences in clinical presentation, course of disease and ultimately survival between ALS patients, either due to differences in genetic background, in the familial as well as in the much more common sporadic form, or due to other individual traits, as concomitant diseases and medications, life style and exogenous exposures.

Understanding these individual differences between patients will lead us to a more personalized approach in the treatment. The first hints for this approach are treatments being developed for patients carrying SOD1 mutations. As more genes are being discovered, treatments directed toward silencing these other genes will follow. Recommendations for changes in life style and environmental exposures for specific groups of patients and asymptomatic gene carriers are close to come. As opposed to the present clumping together of patients with various clinical forms and genetic and environmental backgrounds and offering them a common form of treatment, we can foresee for the next decade a splitting of the syndrome into subtypes, for which different diagnostic and treatment approaches will be used.

\section{References}

1. van der Graaff MM, de Jong JM, Baas F, de Visser M. Upper motor neuron and extra-motor neuron involvement in amyotrophic lateral sclerosis: a clinical and brain imaging review. Neuromuscul Disord. 2009;19:53-8.

2. Qureshi M, Schoenfeld DA, Paliwal Y, Shui A, Cudkowicz M. The natural history of ALS is changing: improved survival. Amyotroph Later Scler. 2009;10:324-31.

3. Logroscino G, Traynor BJ, Hardiman O, Chio A, Mitchell D, Swingler RJ, et al. Incidence of amyotrophic lateral sclerosis in Europe. J Neurol Neurosurg Psychiatry. 2010;81:385-90.

4. Steele JC, McGeer PL. The ALS/PDC syndrome of Guam and the cycad hypothesis. Neurology. 2008;70:1984-90.

5. Kuzuhara S, Kokubo Y. Atypical parkinsonism of Japan: amyotrophic lateral sclerosis-parkinsonism-dementia complex of the Kii peninsula of Japan (Muro disease): an update. Mov Disord. 2005;20:S108-13.

6. Worms PM. The epidemiology of motor neuron diseases: a review of recent studies. J Neurol Sci. 2001;191:3-9.

7. Zoccolella S, Beghi E, Palagano G, Fraddosio A, Guerra V, Samarelli V, et al. Analysis of survival and prognostic factors in amyotrophic lateral sclerosis: a population based study. J Neurol Neurosurg Psychiatry. 2008;79:33-7.

8. Sorenson EJ, Stalker AP, Kurland LT, Windebank AJ. Amyotrophic lateral sclerosis in Olmsted County, Minnesota, 19251998. Neurology. 2002;59:280-2.

9. Raaphorst J, de Visser M, Linssen WJP, de Haan R, Schmand B. The cognitive profile of amyotrophic lateral sclerosis: a metaanalysis. Amyotroph Later Scler. 2010;11:38-45.

10. Kurian KM, Forbes RB, Colville S, Swingler RJ. Cause of death and clinical grading criteria in a cohort of amyotrophic lateral sclerosis cases undergoing autopsy from the Scottish Motor Neurone Disease Register. J Neurol Neurosurg Psychiatry. 2009;80:84-7.

11. Zoccolella S, Beghi E, Palagano G, Fraddosio A, Guerra V, Samarelli V, et al. Predictors of long survival in amyotrophic lateral sclerosis: a population-based study. J Neurol Sci. 2008;268:28-32.

12. Brooks BR, Miller RG, Swash M, Munsat TL. El Escorial revisited: revised criteria for the diagnosis of amyotrophic lateral sclerosis. Amyotroph Lateral Scler Other Motor Neuron Disord. 2000;1:293-9.

13. Traynor BJ, Codd MB, Corr B, Forde C, Frost E, Hardiman OM. Clinical features of amyotrophic lateral sclerosis according to the El Escorial and Airlie House criteria: a population-based study. Arch Neurol. 2000;57:1171-6.

14. de Carvalho M, Dengler R, Eisen A, England JD, Kaji R, Kimura $\mathrm{J}$, et al. Electrodiagnostic criteria for diagnosis of ALS. Clin Neurophysiol. 2008;119:497-503. 
15. Zhang L, Ulug AM, Zimmerman RD, Lin MT, Rubin M, Beal MF. The diagnostic utility of FLAIR imaging in clinically verified amyotrophic lateral sclerosis. J Magn Reson Imaging. 2003;17:521-7.

16. Lule D, Ludolph AC, Kassubek J. MRI-based functional neuroimaging in ALS: an update. Amyotroph Lateral Scler. 2009;10:258-68.

17. Senda J, Ito M, Watanabe H, Atsuta N, Kawai Y, Katsuno M, et al. Correlation between pyramidal tract degeneration and widespread white matter involvement in amyotrophic lateral sclerosis: a study with tractography and diffusion-tensor imaging. Amyotroph Lateral Scler. 2009;10:288-94.

18. Dabby R, Lange DJ, Trojaborg W, Hays AP, Lovelace RE, Brannagan $\mathrm{TH}$, et al. Inclusion body myositis mimicking motor neuron disease. Arch Neurol. 2001;58:1253-6.

19. Nobile-Orazio E, Carpo M, Meucci N. Are there immunologically treatable motor neuron diseases? Amyotroph Lateral Scler Other Motor Neuron Disord. 2001;2:S23-30.

20. Parboosingh JS, Figlewicz DA, Krizus A, Meininger V, Azad NA, Newman DS, et al. Spinobulbar muscular atrophy can mimic ALS: the importance of genetic testing in male patients with atypical ALS. Neurology. 1997;49:568-72.

21. Drory VE, Birnbaum M, Peleg L, Goldman B, Korczyn AD. Hexosaminidase A deficiency is an uncommon cause of a syndrome mimicking amyotrophic lateral sclerosis. Muscle Nerve. 2003;28:109-12.

22. Tashiro K, Kikuchi S, Itoyama Y, Tokumaru Y, Sobue G, Mukai E, et al. Nationwide survey of juvenile muscular atrophy of distal upper extremity (Hirayama disease) in Japan. Amyotroph Lateral Scler. 2006;7:38-45.

23. Beleza-Meireles A, Al-Chalabi A. Genetic studies of amyotrophic lateral sclerosis: controversies and perspectives. Amyotroph Lateral Scler. 2009;10:1-14.

24. Dion PA, Daoud H, Rouleau GA. Genetics of motor neuron disorders: new insights into pathogenetic mechanisms. Nat Rev Genet. 2009;10:769-82.

25. Rosen DR, Siddique T, Patterson D, Figlewicz DA, Sapp P, Hentati $\mathrm{A}$, et al. Mutations in $\mathrm{Cu} / \mathrm{Zn}$ superoxide dismutase gene are associated with familial amyotrophic lateral sclerosis. Nature. 1993;362:59-62.

26. Shaw PJ. Molecular and cellular pathways of neurodegeneration in motor neuron disease. J Neurol Neurosurg Psychiatry. 2005;76:1046-57.

27. Abe K, Aoki M, Ikeda M, Watanabe M, Hirai S, Itoyama Y. Clinical characteristics of familial amyotrophic lateral sclerosis with $\mathrm{Cu} / \mathrm{Zn}$ superoxide dismutase gene mutations. J Neurol Sci. 1996;136:108-16.

28. Neumann M, Sampathu DM, Kwong LK, et al. Ubiquitinated TDP-43 in frontotemporal lobar degeneration and amyotrophic lateral sclerosis. Science. 2006;314:130-3.

29. Mackenzie IR, Bigio EH, Ince PG, et al. Pathological TDP-43 distinguishes sporadic amyotrophic lateral sclerosis from amyotrophic lateral sclerosis with SOD1 mutations. Ann Neurol. 2007;61:427-34.

30. Sreedharan J, Blair IP, Tripathi VB, et al. TDP-43 mutations in familial and sporadic amyotrophic lateral sclerosis. Science. 2008;319:1668-72.

31. Yokoseki A, Shiga A, Tan CF, Tagawa A, Kaneko H, Koyama A, et al. TDP-43 mutation in familial amyotrophic lateral sclerosis. Ann Neurol. 2008;63:538-42.

32. Kabashi E, Valdmanis PN, Dion P, Spiegelman D, McConkey BJ, Velde $\mathrm{C}$, et al. TARDBP mutations in individuals with sporadic and familial amyotrophic lateral sclerosis. Nat Genet. 2008;40:572-4.

33. Wegorzewska I, Bell S, Cairns NJ, Miller TM, Baloh RH. TDP43 mutant transgenic mice develop features of ALS and frontotemporal degeneration. Proc Natl Acad Sci. 2009;106:18809-14.
34. Kwiatkowski Jr TJ, Bosco DA, Leclerc AL, et al. Mutations in the FUS/TLS gene on chromosome 16 cause familial amyotrophic lateral sclerosis. Science. 2009;323:1205-8.

35. Vance C, Rogelj B, Hortobagyi T, et al. Mutations in FUS, an RNA processing protein, cause familial amyotrophic lateral sclerosis type 6. Science. 2009;323:1208-11.

36. Belzil VV, Valdmanis PN, Dion PA, et al. Mutations in FUS cause FALS and SALS in French and French Canadian populations. Neurology. 2009;73:1176-9.

37. The International HapMap Consortium. A haplotype map of the human genome. Nature. 2005;437:1299-320.

38. Dunckley T, Huentelman MJ, Craig DW, Pearson JV, Szelinger $\mathrm{S}$, Joshipura $\mathrm{K}$, et al. Whole-genome analysis of sporadic amyotrophic lateral sclerosis. N Engl J Med. 2007;357:775-88.

39. van Es MA, Veldink JH, Saris CG, Blauw HM, van Vught PW, Birve A, et al. Genome-wide association study identifies 19p13.3 (UNC13A) and 9p21.2 as susceptibility loci for sporadic amyotrophic lateral sclerosis. Nat Genet. 2009;41:1083-7.

40. Blauw HM, Veldink JH, van Es MA, van Vught PW, Saris CG, van der Zwaag, et al. Copy-number variation in sporadic amyotrophic lateral sclerosis: a genome-wide screen. Lancet Neurol. 2008;7:319-26.

41. Chio A, Schymick JC, Restagno G, Scholz SW, Lombardo F, Lai $\mathrm{SL}$, et al. A two-stage genome-wide association study of sporadic amyotrophic lateral sclerosis. Hum Mol Genet. 2009;18:1524-32.

42. Landers JE, Melki J, Meininger V, Glass JD, van den Berg LH, van Es MA, et al. Reduced expression of the Kinesin-associated protein 3 (KIFAP3) gene increases survival in sporadic amyotrophic lateral sclerosis. Proc Natl Acad Sci. 2009;106:9004-9.

43. Gros-Louis F, Andersen PM, Dupre N, Urushitani M, Dion P, Souchon F, et al. Chromogranin B P413L variant as risk factor and modifier of disease onset for amyotrophic lateral sclerosis. Proc Natl Acad Sci. 2009;106:21777-82.

44. Gallo V, Bueno-De-Mesquita HB, Vermeulen R, Andersen PM, Kyrozis A, Linseisen J. Smoking and risk for amyotrophic lateral sclerosis: analysis of the EPIC cohort. Ann Neurol. 2009;65:378 85 .

45. Armon C. Smoking may be considered an established risk factor for sporadic ALS. Neurology. 2009;73:1693-8.

46. Armon C. An evidence-based medicine approach to the evaluation of the role of exogenous risk factors in sporadic amyotrophic lateral sclerosis. Neuroepidemiology. 2003;22:217-28.

47. Sutedja NA, Fischer K, Veldink JH, van der Heijden GJMG, Kromhout H, Heederik D, et al. What we truly know about occupation as a risk factor for ALS: a critical and systematic review. Amyotroph Lateral Scler. 2009;10:295-301.

48. Horner RD, Kamins KG, Feussner JR, Grambow SC, HoffLidquist J, Harati Y, et al. Occurrence of amyotrophic lateral sclerosis among Gulf War veterans. Neurology. 2003;61:742-9.

49. Haley RW. Excess incidence of ALS in young Gulf War veterans. Neurology. 2003;61:750-6.

50. Chiò A, Benzi G, Dossena M, Mutani R, Mora G. Severely increased risk of amyotrophic lateral sclerosis among Italian professional football players. Brain. 2005;128:472-6.

51. Chio A, Calvo A, Dossena M, Ghiglione P, Mutani R, Mora G. ALS in Italian professional soccer players: the risk is still present and could be soccer-specific. Amyotroph Lateral Scler. 2009;10:205-9.

52. Hyams KC, Brown M, White DS. Resolving disputes about toxicological risks during military conflict: the US Gulf War experience. Toxicol Rev. 2005;24:167-80.

53. Armon C. Sports and trauma in amyotrophic lateral sclerosis revisited. J Neurol Sci. 2007;262:45-53.

54. Edwards IR, Star K, Kiuru A. Statins, neuromuscular degenerative disease and an amyotrophic lateral sclerosis-like syndrome: 
an analysis of individual case safety reports from vigibase. Drug Saf. 2007;30:515-25.

55. Colman E, Szarfman A, Wyeth J, Mosholder A, Jillapalli D, Levine J, et al. An evaluation of a data mining signal for amyotrophic lateral sclerosis and statins detected in FDA's spontaneous adverse event reporting system. Pharmacoepidemiol Drug Saf. 2008;17:1068-76.

56. Dupuis L, Corcia P, Fergani A, et al. Dyslipidemia is a protective factor in amyotrophic lateral sclerosis. Neurology. 2008;70:1004-9.

57. Keizman D, Ish-Shalom M, Berliner S, Maimon N, Vered Y, Artamonov I, et al. Low uric acid levels in serum of patients with ALS: further evidence for oxidative stress? J Neurol Sci. 2009;285:95-9.

58. Jawaid A, Salamone AR, Strutt AM, Murthy SB, Wheaton M, McDowell EJ et al. ALS disease onset may occur later in patients with pre-morbid diabetes mellitus. Eur J Neurol 2010 Epub

59. Bruijn LI, Becher MW, Lee MK, Anderson KL, Jenkins NA, Copeland NG, et al. ALS-linked SOD1 mutant G85R mediates damage to astrocytes and promotes rapidly progressive disease with SOD1-containing inclusions. Neuron. 1997;18:327-38.

60. Gurney ME, Pu H, Chiu AY, DalCanto MC, Polchow CY, Alexander DD, et al. Motor neuron degeneration in mice that express human $\mathrm{Cu}, \mathrm{Zn}$ superoxide dismutase mutation. Science. 1994;264:1772-5

61. Wong PC, Pardo CA, Borchelt DR, Lee MK, Copeland NG, Jenkins NA, et al. An adverse property of a familial ALS-linked SOD1 mutation causes motor neuron disease characterized by vacuolar degeneration of mitochondria. Neuron. 1995;14:110516.

62. Bruijn LI, Houseweart MK, Kato S, Anderson KL, Anderson $\mathrm{SD}$, Ohama E, et al. Aggregation and motor neuron toxicity of an ALS-linked SOD1 mutant independent from wild-type SOD1. Science. 1998;281:1851-54.

63. Gong YH, Parsadanian AS, Andreeva A, et al. Restricted expression of $\mathrm{G} 86 \mathrm{R} \mathrm{Cu} / \mathrm{Zn}$ superoxide dismutase in astrocytes results in astrocytosis but does not cause motoneuron degeneration. J Neurosci. 2000;20:660-5.

64. Pramatarova A, Laganiere J, Roussel J, Brisebois K, Rouleau GA. Neuron-specific expression of mutant superoxide dismutase 1 in transgenic mice does not lead to motor neuron impairment. J Neurosci. 2001;21:3369-74.

65. Lino MM, Schneider C, Caroni P. Accumulation of SOD1 mutant in postnatal motor neurons does not cause motor neuron pathology of motoneuron disease. J Neurosci. 2002;22:4825-32.

66. Clement AM, Nguyen MD, Roberts EA, Garcia ML, Boillee S, Rule M, et al. Wild-type nonneuronal cells extended survival of SOD1 mutant motor neurons in ALS mice. Science. 2003;302:113-7.

67. Nagai M, Re DB, Nagata T, Chalazonitis A, Jessell TM, Wichterle $\mathrm{H}$, et al. Astrocytes expressing ALS-linked mutated SOD1 release factors selectively toxic to motor neurons. Nat Neurosci. 2007;10:615-22.

68. Beers DR, Henkel JS, Xiao Q, Zhao W, Wang J, Yen AA, et al. Wild-type microglia extend survival in PU.1 knockout mice with familial amyotrophic lateral sclerosis. Proc Natl Acad Sci. 2006;103:16021-6

69. Boillee S, Yamanaka K, Lobsiger CS, Copeland NG, Jenkins NA, Kassiotis G, et al. Onset and progression in inherited ALS determined by motor neurons and microglia. Science. 2006;312:1389-92.

70. Yamanaka K, Chun SJ, Boillee S, Fujimori-Tonou N, Yamashita $\mathrm{H}$, Gutmann DH, et al. Astrocytes as determinants of disease progression in inherited amyotrophic lateral sclerosis. Nat Neurosci. 2008;11:251-3.

71. Yamanaka K, Boillee S, Roberts EA, Garcia ML, McAlonisDownes M, Mikse OR, et al. Mutant SOD1 in cell types other than motor neurons and oligodendrocytes accelerates onset of disease in ALS mice. Proc Natl Acad Sci. 2008;105:7594-9.

72. Spreux-Varoquaux O, Bensimon G, Lacomblez L, et al. Glutamate levels in cerebrospinal fluid in amyotrophic lateral sclerosis: a reappraisal using a new HPLC method with colometric detection in a large cohort of patients. J Neurol Sci. 2002;193:73-8.

73. Rothstein JD, Van Kammen M, Levey AL, Martin LJ, Kuncl RW. Selective loss of glial glutamate transporter GLT-1 in amyotrophic lateral sclerosis. Ann Neurol. 1995;38:73-84.

74. Beal MF, Ferrante RJ, Browne SE, et al. Increased 3-nitrotyrosine in both sporadic and familial amyotrophic lateral sclerosis. Ann Neurol. 1997;42:644-54.

75. Arai T, Hasegawa M, Akiyama H, et al. TDP-43 is a component of ubiquitin-positive tau-negative inclusions in frontotemporal lobar degeneration and amyotrophic lateral sclerosis. Biochem Biophys Res Commun. 2006;35:602-11.

76. Tan CF, Eguchi H, Tagawa A, et al. TDP-43 immunoreactivity in neuronal inclusions in familial amyotrophic lateral sclerosis with or without SOD1 gene mutation. Acta Neuropathol. 2007;113:535-42.

77. Shi P, Gal J, Kwinter DM, Liu X, Zhu H. Mitochondrial dysfunction in amyotrophic lateral sclerosis. Biochim Biophys Acta. 2010;1802:45-51.

78. Klivenyi P, Ferrante RJ, Matthews RT, et al. Neuroprotective effects of creatine in a transgenic animal model of amyotrophic lateral sclerosis. Nat Med. 1999;5:347-50.

79. Rosenfeld J, King RM, Jackson CE, Bedlack RS, Barohn RJ, Dick A, et al. Creatine monohydrate in ALS: Effects on strength, fatigue, respiratory status and ALSFRS. Amyotroph Lateral Scler. 2008;9:266-72.

80. Bruijn LI, Miller TM, Cleveland DW. Unraveling the mechanisms involved in motor neuron degeneration in ALS. Annu Rev Neurosci. 2004;27:723-49.

81. Rothstein JD. Current hypotheses for the underlying biology of amyotrophic lateral sclerosis. Ann Neurol. 2009;65:S3-9.

82. Qureshi M, Schoenfeld DA, Paliwal Y, Shui A, Cudkowicz ME. The natural history of ALS is changing: improved survival. Amyotroph Lateral Scler. 2009;10:324-31.

83. Cheah BC, Boland RA, Brodaty NE, Zoing MC, Jeffery SE, MacKenzie DK, et al. INSPIRATIonAL-INSPIRAtory muscle training in amyotrophic lateral sclerosis. Amyotroph Lateral Scler. 2009;10:384-92

84. Bourke SC, Tomlinson M, Williams TL, Bullock RE, Shaw PJ, Gibson GJ. Effects of non-invasive ventilation on survival and quality of life in patients with amyotrophic lateral sclerosis. Lancet Neurol. 2006;5:140-57.

85. Heffernan C, Jenkinson C, Holmes T, Macleod H, Kinnear W, Oliver D, et al. Management of respiration in MND/ALS patients: an evidence-based review. Amyotroph Lateral Scler. 2006; 7:5-15.

86. Carratu P, Spicuzza L, Cassano A, Maniscalco M, Gadaleta F, Lacedonia D, et al. Early treatment with noninvasive positive pressure ventilation prolongs survival in amyotrophic lateral sclerosis patients with nocturnal respiratory insufficiency. Orphanet J Rare Dis. 2009;10:4-10.

87. Radunovic A, Annane D, Jewitt K, Mustfa N. Mechanical ventilation for amyotrophic lateral sclerosis / motor neuron disease. Cochrane Database Syst Rev 2009

88. Miller RG, Jackson CE, Kasarskis EJ, England JD, Forshew D, Johnston W, et al. Practice Parameter update: the care of the patient with amyotrophic lateral sclerosis: drug, nutritional, and respiratory therapies (an evidence-based review). Neurology. 2009;73:1218-26

89. Onders RP, Elmo M, Khansarinia S, Bowman B, Yee J, Road J, et al. Complete world-wide operative experience in laparoscopic diaphragm pacing: results and differences in spinal cord injured 
patients and amyotrophic lateral sclerosis patients. Surg Endosc. 2009;23:1433-40.

90. Vaisman N, Lusaus M, Nefussy B, Niv E, Comaheshter D, Hallack R, et al. Do patients with amyotrophic lateral sclerosis (ALS) have increased energy needs? J Neurol Sci. 2009;279:26-9.

91. Funalot B, Desport JC, Sturtz F, Camu W, Couratier P. High metabolic level in patients with familial amyotrophic lateral sclerosis. Amyotroph Lateral Scler. 2009;10:113-7.

92. Daly JJ, Wolpaw JR. Brain-computer interfaces in neurological rehabilitation. Lancet Neurol. 2008;7:1032-43.

93. Drory VE, Goltsman E, Goldman Reznik J, Mosek A, Korczyn $\mathrm{AD}$. The value of muscle exercise in patients with amyotrophic lateral sclerosis. J Neurol Sci. 2001;191:133-7.

94. Dal Bello-Haas VP, Florence JM, Kloos AD, et al. A randomized controlled trial of resistance exercise in individuals with ALS. Neurology. 2007;68:2003-7.

95. Traynor BJ, Alexander M, Corr B, Frost E, Hardiman O. Effect of a multidisciplinary amyotrophic lateral sclerosis (ALS) clinic on ALS survival: a population based study, 1996-2000. J Neurol Neurosurg Psychiatry. 2003;74:1258-61.

96. Bensimon G, Lacomblez L, Meininger V. A controlled trial of riluzole in amyotrophic lateral sclerosis. ALS/Riluzole Study Group. N Engl J Med. 1994;330:585-91.

97. Lacomblez L, Bensimon G, Leigh PN, Guillet P, Meininger V. Dose-ranging study of riluzole in amyotrophic lateral sclerosis. Amyotrophic Lateral Sclerosis/Riluzole Study Group II. Lancet. 1996;347:1425-31.

98. Bellingham MC. A review of the neural mechanisms of action and clinical efficiency of riluzole in treating amyotrophic lateral sclerosis: what have we learned in the last decade? CNS Neurosci Ther 2010 Epub

99. Miller RG, Mitchell JD, Lyon M, Moore DH. Riluzole for amyotrophic lateral sclerosis (ALS)/motor neuron disease (MND). Cochrane Database Syst Rev. 2007:CD001447.

100. Stone CA, O'Leary N. Systematic review of the effectiveness of botulinum toxin or radiotherapy for sialorrhea in patients with amyotrophic lateral sclerosis. J Pain Symptom Manage. 2009;37:246-58.

101. Bedlack RS, Pastula DM, Hawes J, Heydt D. Open-label trial of levetiracetam for cramps and spasticity in patients with motor neuron disease. Amyotroph Lateral Scler. 2009;10:205-9.

102. Rabkin JG, Gordon PH, McElhiney M, Rabkin R, Chew S, Mitsumoto H. Modafinil treatment of fatigue in patients with ALS: a placebo-controlled study. Muscle Nerve. 2009;39:297-303.

103. Pascuzzi RM, Shefner J, Chappell AS, Bjerke JS, Tamura R, Chaudhry V, et al. A phase II trial of talampanel in subjects with amyotrophic lateral sclerosis. Amyotroph Lateral Scler. 2010;11:266-71.

104. Lee SG, Emdad L, Gupta P, Sarkar D, Borjabad A, Volsky DJ, et al. Mechanism of ceftriaxone induction of excitatory amino acid transporter-2 expression and glutamate uptake in primary human astrocytes. J Biol Chem. 2008;283:13116-23.

105. Rothstein JD, Patel S, Regan MR, Haenggeli C, Huang YH, Bergles DE, et al. $\beta$-lactam antibiotics offer neuroprotection by increasing glutamate transporter expression. Nature. 2005;433:73-7.
106. Rosen H. Dextromethorphan/quinidine sulfate for pseudobulbar affect. Drugs Today. 2008;44:661-8.

107. Oosthuyse B, Moons L, Storkebaum E, Beck H, Nuyens D, Brusselmans K, et al. Deletion of the hypoxia-response element in the vascular endothelial growth factor promoter causes motor neuron degeneration. Nat Genet. 2001;28:131-8.

108. Wang Y, Mao XO, Xie L, Banwait S, Marti HH, Greenberg DA, et al. Vascular endothelial growth factor overexpression delays neurodegeneration and prolongs survival in amyotrophic lateral sclerosis mice. J Neurosci. 2007;27:304-7.

109. Azzouz M, Ralph GS, Storkebaum E, Walmsley LE, Mitrophanous KA, Kingsman SM, et al. VEGF delivery with retrogradely transported lentivector prolongs survival in a mouse ALS model. Nature. 2004;429:413-7.

110. Lambrechts D, Poesen K, Fernandez-Santiago R, Al-Chalabi A, Del Bo R, Van Vught PW, et al. Meta-analysis of vascular endothelial growth factor variations in amyotrophic lateral sclerosis: increased susceptibility in male carriers of the2578AA genotype. J Med Genet. 2009;46:840-6.

111. Lanka V, Wieland S, Barber J, Cudkowicz M. Arimoclomol: a potential therapy under development for ALS. Expert Opin Investig Drugs. 2009;18:1907-18.

112. Cudkowicz ME, Shefner JM, Simpson E, Grasso D, Yu H, Zhang H, et al. Arimoclomol at dosages up to $300 \mathrm{mg} /$ day is well tolerated and safe in amyotrophic lateral sclerosis. Muscle Nerve. 2008;38:837-44.

113. Gribkoff VK, Bozik ME. KNS-760704 [(6R)-4, 5, 6, 7 tetrahydro-N6-propyl-2, 6-benzothiazole-diamine dihydrochloride monohydrate] for the treatment of amyotrophic lateral sclerosis. CNS Neurosci Ther. 2008;14:215-28.

114. Bozik M, Ingersoll E, Volles L, Mather J, Amburgey C, Moritz J, et al. KNS-760704-CL201, part 1: a 12-week phase 2 study of the safety, tolerability, and clinical effects of KNS 760704 in ALS subjects. Amyotroph Lateral Scler. 2009;10: S28-29.

115. Bordet T, Buisson B, Michaud M, Drouot C, Galea P, Delaage P, et al. Identification and characterization of cholest-4-en-3-one, oxime (RTO19622), a novel drug candidate for amyotrophic lateral sclerosis. J Pharmacol Exp Ther. 2007;322:709-20.

116. Xu L, Yan J, Chen D, Welsh AM, Hazel T, Johe K, et al. Human neuronal stem cells grafts ameliorate motor neuron disease in SOD-1 transgenic rats. Transplantation. 2006;82:86575 .

117. Martinez HR, Gonzales-Garza MT, Moreno-Cuevas JE, Caro E, Gutierrez-Jimenez E, Segura JJ. Stem-cell transplantation into the frontal motor cortex in amyotrophic lateral sclerosis patients. Cytotherapy. 2009;11:26-34.

118. Mazzini L, Ferrero I, Luparello V, Rustichelli D, Gunetti M, Mareschi K, et al. Mesenchymal stem cell transplantation in amyotrophic lateral sclerosis: a Phase I clinical trial. Exp Neurol. 2010;223:229-37.

119. Dimos JT, Rodolfa KT, Niakan KK, Weisenthal LM, Mitsumoto $\mathrm{H}$, Chung $\mathrm{W}$, et al. Induced pluripotent stem cells generated from patients with ALS can be differentiated into motor neurons. Science. 2008;321:1218-21. 